\title{
Participation in Juvenile Idiopathic Arthritis
}

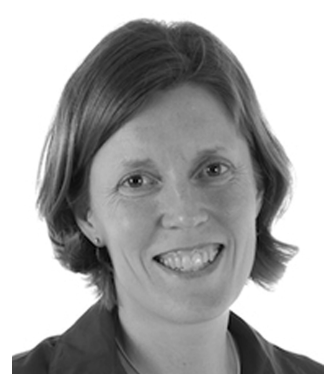

Juvenile idiopathic arthritis (JIA) can influence all aspects of a child's life as well as that of the family, and healthcare providers increasingly recognize that improved health-related quality of life (HRQOL), physical activity, and community participation are important treatment goals.

Physical activity is essential for optimal physical, emotional, and psychosocial development in childhood. Children with JIA are less physically active than their healthy peers, spend more time sleeping, perform fewer strenuous activities, and are less likely to participate in organized sports ${ }^{1,2,3,4}$. Most children with JIA do not meet the current international physical activity recommendation of $60 \mathrm{~min}$ daily moderately vigorous physical activity, which is important for health-related outcomes ${ }^{5,6,7}$.

Community participation is also recognized to be important for children's development and functioning. The World Health Organization (WHO) has acknowledged the importance of social participation with its International Classification of Functioning, Disability and Health (ICF) model ${ }^{8}$. A derived classification for children and youth (ICF-CY) was developed in $2007^{9}$. Community participation and leisure participation is an understudied area of JIA: A recent systematic review on leisure participation in children with JIA included only 12 articles, most of which described participation in physical rather than social activities ${ }^{10}$. In this issue of The Journal, Cavallo, et al report on leisure activity participation in children and adolescents with JIA ${ }^{11}$.

In their 2014 systematic review, Cavallo and colleagues found that children with JIA participated less in both social and physical leisure activities as compared to healthy peers ${ }^{10}$. They identified potential determinants of leisure participation including sociodemographic (age, sex), anthropometric (height, weight), and disease-related (JIA subtype, disease duration, pain, number of swollen or painful joints, stiffness, fatigue, well-being) factors ${ }^{10}$. The systematic review high-lighted the paucity of literature on leisure participation in JIA. The assessment of leisure participation was largely by self-report and limited to physical or social activities. No study reported on personal, contextual, or environmental factors as potential determinants or influencers of leisure participation ${ }^{10}$.

In their current report, Cavallo and colleagues describe their findings from a cross-sectional study characterizing leisure activity participation in 107 children with JIA aged 8 to 17 years. Their stated objective was to describe leisure activities in children with JIA in terms of diversity, intensity, and enjoyment, and to identify potential determinants. The authors used the self-administered version of the Children's Assessment of Participation and Enjoyment (CAPE) to measure participation in leisure activities in children with JIA and their age-matched siblings. The CAPE is a validated questionnaire designed to examine how children and youth participate in everyday activities outside of their school curriculum $^{12}$. It measures multiple dimensions of participation, including participation diversity, intensity, with whom and where participation occurs, and enjoyment. It includes 55 informal and formal activities that can be organized into 5 activity types: recreational, active physical, social, skill-based, and self-improvement ${ }^{12}$.

Cavallo and colleagues found that children with JIA were more often engaged in informal rather than formal leisure activities and were most often involved in social and recreational activities. The top 5 daily activities were listening to music, doing homework, watching television, playing with pets, and playing computer/video games. Those with active arthritis (flare) displayed less diverse, less intense participation in active physical activities, and less frequent involvement in informal activities compared to those who reported no active JIA symptoms. Compared to their healthy siblings, children with JIA participated less in physical activities. Compared to a reference sample of healthy Canadian children, children with JIA displayed less diverse and less intense participation in informal activities; similar participation in social activities; similar enjoyment and diversity in active physical activities, but less frequent participation. These results are in keeping with current literature, which suggests children with JIA spend the majority of their leisure

See Leisure in JIA, page 1708

Personal non-commercial use only. The Journal of Rheumatology Copyright (C) 2015. All rights reserved. 
time engaged in social and recreational activities and they are not as physically active as their healthy peers ${ }^{2,4,10}$.

There are several limitations to the current study, chief of which is the cross-sectional nature and lack of measures of function (e.g., Child Health Assessment Questionnaire, WHO ICF activity and participation) or HRQOL measure, making it difficult to interpret the clinical significance of the results. However, the study highlights the need to consider participation when assessing a child with JIA for functioning/disability.

Participation is best measured with the ICF, a classification of health and health-related domains that serves as a framework for measuring health and disability at both individual and population levels ${ }^{8}$. The individual differentiation between activity and participation is made in the context of both personal and environmental factors. Participation is defined as one of 3 major components of functioning: activities, body functions, and body structures ${ }^{8}$.

Participation restrictions contribute to the experience of disability. In this model, the participation component can be influenced by, and may influence the other components of, functioning, i.e., activities, body functions, and body structures (Figure 1). For example, a child with JIA may have restricted activity and leisure participation due to an impairment of body structure or function (e.g., joint swelling, joint pain, reduced range of motion, muscle weakness, anemia, fatigue), which may be influenced by personal factors (e.g., age, sex, motivation). Environmental factors (e.g., family function, peer support, community services, healthcare services) may act as facilitators or barriers to a child's participation in activities (Table 1).

The ICF model provides an excellent framework for measuring health and disability in children with JIA. It measures the effects of JIA on the functioning of the individual child; accepts that disability (disease) is variable, sometimes permanent, and often transient; and suggests that environmental factors play a significant role in the experience of health and disability.

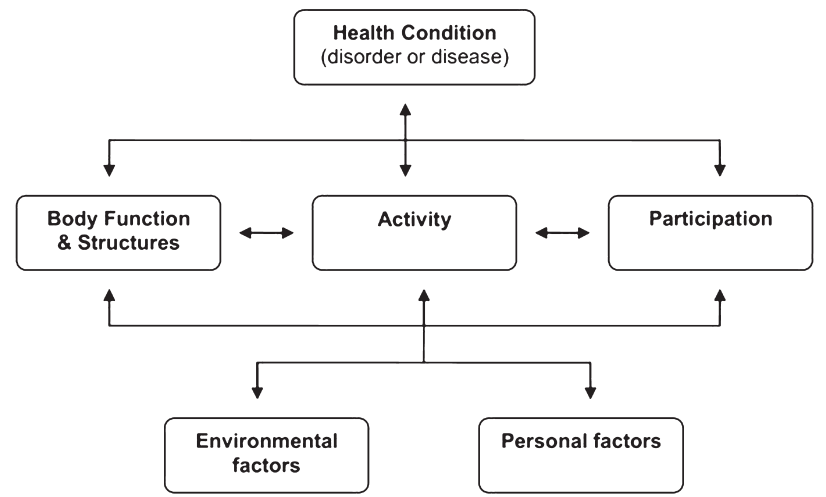

Figure 1. World Health Organization (WHO) International Classification of Functioning, Disability and Health model. From the WHO. International Classification of Functioning, Disability and Health (ICF). Geneva: 2001 with permission.
Table 1. International Classification of Functioning, Disability and Health model components and domains, from the World Health Organization. Geneva: World Health Organization; 20018 ${ }^{8}$ : with permission.

\begin{tabular}{|c|c|}
\hline Function & Activity \\
\hline Body function & Activities and participation \\
\hline Mental functions & Learning and applying knowledge \\
\hline Sensory functions and pain & General tasks and demands \\
\hline Voice and speech functions & Communication \\
\hline $\begin{array}{l}\text { Functions of the cardiovascular, } \\
\text { hematological, immunological, } \\
\text { and respiratory systems }\end{array}$ & Mobility \\
\hline $\begin{array}{l}\text { Functions of the digestive, } \\
\text { metabolic, endocrine systems }\end{array}$ & Self-care \\
\hline $\begin{array}{l}\text { Genitourinary and reproductive } \\
\text { functions }\end{array}$ & Domestic life \\
\hline $\begin{array}{l}\text { Neuromusculoskeletal and } \\
\text { movement-related functions }\end{array}$ & $\begin{array}{l}\text { Interpersonal interactions and } \\
\text { relationships }\end{array}$ \\
\hline $\begin{array}{l}\text { Functions of the skin and related } \\
\text { structures }\end{array}$ & $\begin{array}{l}\text { Major life areas } \\
\text { Community, social, and civic life }\end{array}$ \\
\hline Body structure & Environmental factors \\
\hline Structure of the nervous system & Products and technology \\
\hline $\begin{array}{l}\text { The eye, ear, and related } \\
\text { structures }\end{array}$ & $\begin{array}{l}\text { Natural environment and human-made } \\
\text { changes to environment }\end{array}$ \\
\hline $\begin{array}{l}\text { Structures involved in voice } \\
\text { and speech }\end{array}$ & Support and relationships \\
\hline $\begin{array}{l}\text { Structure of the cardiovascular, } \\
\text { immunological, and respiratory } \\
\text { systems }\end{array}$ & Attitudes \\
\hline $\begin{array}{l}\text { Structures related to the digestive, } \\
\text { metabolic, and endocrine systems }\end{array}$ & Services, systems, and policies \\
\hline $\begin{array}{l}\text { Structure related to genitourinary } \\
\text { and reproductive systems }\end{array}$ & \\
\hline Structures related to movement & \\
\hline Skin and related structures & \\
\hline
\end{tabular}

There are many musculoskeletal ICF core sets for use in adults including rheumatoid arthritis, acute inflammatory arthritis, ankylosing spondylitis, and osteoarthritis ${ }^{13,14,15,16}$. These core sets were developed by physicians and patients using a systematic consensus approach to capture the short list of ICF categories that are essential to describe the disability experience of a person with a specific disease condition.

At present, there are no pediatric ICF core sets. In the future, use of the ICF-CY and development of a JIA core set may lead to improved understanding of the potential effects of JIA on children's activities and participation and ultimately may lead to improved care and advocacy.

Cavallo and colleagues have brought much-needed attention to leisure participation in children with JIA. Their cross-sectional study found decreased participation in children with JIA, especially those with active arthritis. Longitudinal studies are needed to study the relationship between disease trajectories (diagnosis, remission, flares) and participation. The ICF model provides a framework for future study.

Personal non-commercial use only. The Journal of Rheumatology Copyright $@$ 2015. All rights reserved 
KRISTIN M. HOUGHTON, MD, MSc, FRCPC, Dip Sports Med, Clinical Associate Professor,

Division of Rheumatology,

Department of Pediatrics, University of British Columbia,

Vancouver, British Columbia, Canada.

Address correspondence to Prof. K.M. Houghton, British Columbia Children's Hospital, Rheumatology, K4-119 Ambulatory Care Building, BCCH 4480 Oak St., Vancouver, British Columbia V6H 3V4, Canada.

E-mail: khoughton@cw.bc.ca

\section{REFERENCES}

1. Houghton K. Physical activity, physical fitness, and exercise therapy in children with juvenile idiopathic arthritis. Phys Sportsmed 2012;40:77-82.

2. Henderson CJ, Lovell DJ, Specker BL, Campaigne BN. Physical activity in children with juvenile rheumatoid arthritis: quantification and evaluation. Arthritis Rheum 1995;8:114-9.

3. Lelieveld OT, Armbrust W, van Leeuwen MA, Duppen N, Geertzen $\mathrm{JH}$, Sauer PJ, et al. Physical activity in adolescents with juvenile idiopathic arthritis. Arthritis Rheum 2008;59:1379-84.

4. Hebestreit H, Müller-Scholden J, Huppertz H. Aerobic fitness and physical activity in patients with HLA-B27 positive juvenile spondyloarthropathy that is inactive or in remission. J Rheumatol 1998;25:1626-33.

5. Lipnowski S, LeBlanc CM; Canadian Paediatric Society, Healthy Active Living and Sports Medicine Committee. Healthy active living: Physical activity guidelines for children and adolescents. Paediatr Child Health 2012;17:209-12.

6. 2008 physical activity guidelines for Americans. Washington, DC: US Department of Health and Human Services; 2008:15-34.

7. World Health Organization. Global recommendations on physical activity for health. Geneva: WHO Publications; 2010.
8. World Health Organization. International classification of functioning, disability and health (ICF). Geneva: World Health Organization; 2001.

9. World Health Organization. International classification of functioning, disability, and health: children and youth version. ICF-CY: World Health Organization; 2007.

10. Cavallo S, April KT, Grandpierre V, Majnemer A, Feldman DE. Leisure in children and adolescents with juvenile idiopathic arthritis: a systematic review. PloS One 2014;9:e104642.

11. Cavallo S, Majnemer A, Duffy C, Ehrmann Feldman D. Participation in leisure activities by children and adolescents with juvenile idiopathic arthritis. J Rheumatol 2015;42:1708-15.

12. King G, Law M, King S, Hurley P, Rosenbaum P, Hanna S, et al. Children's assessment of participation and enjoyment (CAPE) and preferences for activities of children (PAC) [manual]. San Antonio: Harcourt Assessment Inc.; 2004.

13. Stucki G, Cieza A, Geyh S, Battistella L, Lloyd J, Symmons D, et al. ICF core sets for rheumatoid arthritis. J Rehabil Med 2004;44 Suppl:87-93.

14. Dreinhöferr K, Stucki G, Ewert T, Huber E, Ebenbichler G, Gutenbrunner C, et al. ICF Core Sets for osteoarthritis. J Rehabil Med 2004;Suppl:75-80.

15. Boonen A, Braun Jr, van der Horst Bruinsma IE, Huang F, Maksymowych W, Kostanjsek N, et al. ASAS/WHO ICF core sets for ankylosing spondylitis (AS): How to classify the impact of AS on functioning and health. Ann Rheum Dis 2010;69:102-7.

16. Grill E, Zochling J, Stucki G, Mittrach R, Scheuringer M, Liman W, et al. International classification of functioning, disability and health (ICF) core set for patients with acute arthritis. Clin Exp Rheumatol 2007;25:252-8.

J Rheumatol 2015;42:1545-7; doi:10.3899/jrheum.150438 